\title{
Stroke prevention in atrial fibrillation
}

\author{
Warfarin is most effective when the INR lies between 2.0 and 4.0
}

$\mathrm{E}$ pidemiological research has established that non-rheumatic atrial fibrillation is an important risk factor for stroke. It increases the risk about fivefold and is particularly important in elderly people, in whom the prevalence of atrial fibrillation is high. ${ }^{1}$ Randomised trials have shown that this risk is largely reversed by anticoagulation..$^{2}$ The prescription of warfarin for stroke prevention has increased, but concerns about the risks of bleeding continue to dampen enthusiasm for its wider use. ${ }^{4}$ Targeting those with a higher risk of stroke ensures that only those with most to gain from anticoagulation are exposed to its risks. ${ }^{2}$ However, reducing the risks will require safer anticoagulation strategies. Three have been tested in recent research: very low intensity warfarin, aspirin, and a combination of these two treatments.

Information about the efficacy of these strategies is now available from both observational and experimental studies. In a case-control analysis 74 patients with non-rheumatic atrial fibrillation who suffered a stroke while taking warfarin were compared with 222 patients with atrial fibrillation who had not had a stroke while anticoagulated. ${ }^{5}$ In these patients, the risk of ischaemic stroke, adjusted for other determinants of stroke, increased the further the international normalised ratio fell below 2.0. At a ratio of 1.7 the risk of stroke was twice as high as at a ratio of 2.0. At a ratio of 1.3 it was six times higher. Maximum benefit was achieved at a ratio of 2.0, with no increase in protection against stroke at higher ratios.

Adding aspirin does not compensate for the reduced efficacy of low intensity anticoagulation. The SPAF (stroke prevention in atrial fibrillation) III randomised trial compared adjusted dose warfarin (international normalised ratio 2.0-3.0) to a combination of fixed dose warfarin (ratio 1.2-1.5 for initial dose adjustment) and aspirin $(325 \mathrm{mg} /$ day $){ }^{6}$ All the patients had at least one other risk factor for stroke besides atrial fibrillation. The trial stopped early because of a significantly higher rate of ischaemic stroke in those taking the combination of fixed dose warfarin and aspirin: the rate of stroke in the patients taking the combination treatment was $7.9 \%$ a year compared with $1.9 \%$ a year in those taking adjusted dose warfarin (absolute rate difference $6.0 \%$, relative risk reduction $74 \%$, number needed to treat with adjusted dose warfarin 17). There was no significant difference in rates of major haemorrhage between the two groups.

In a recent pooled analysis of the early randomised trials, aspirin alone reduced the risk of stroke by $21 \%{ }^{7}$
This estimate was barely significant $(95 \%$ confidence interval 0 to $38 \%$ ). The SPAF III study makes clear that adjusted dose warfarin is much more effective than aspirin. This may seem at odds with the earlier SPAF II randomised trial, which compared warfarin with aspirin alone and included patients without important risk factors in addition to atrial fibrillation. ${ }^{8}$ In that study warfarin was more effective than aspirin for preventing ischaemic stroke, but in older patients its benefits were cancelled by a higher rate of intracranial haemorrhage. However, the target international normalised ratio for patients treated with warfarin in SPAF II was 2.0-4.5.

There is increasing evidence that the risk of serious haemorrhage rises at ratios above 4.0. ${ }^{9}$ Provided the international normalised ratio can be kept below this level, warfarin should be preferred to aspirin except in patients with a low risk of stroke or a high risk of haemorrhage. Patients with a low risk of stroke are those aged under 65 and without hypertension, diabetes, or a history of stroke or transient ischaemic attack. ${ }^{2}$ Patients with a high risk of haemorrhage include those with serious comorbidity and those in whom control of anticoagulation is difficult. ${ }^{9}{ }^{10}$ If the risk of haemorrhage is high, then aspirin offers a safer but less effective alternative to anticoagulation.

For those at higher risk, including older patients, adjusted dose warfarin is the treatment of choice. Existing guidelines recommend a target international normalised ratio for warfarin anticoagulation of 2.0-3.0. ${ }^{11}$ To reduce the risk of bleeding, some doctors have pragmatically opted for less intensive targets. ${ }^{12}$ This strategy can no longer be justified. The aim of treatment should be to prevent the international normalised ratio falling below 2.0 or rising above 4.0. ${ }^{513}$ To achieve this with margin for error at both ends of the range, Rosendaal has suggested a target of 2.5-3.5. ${ }^{14}$ Cautious doctors may prefer to aim for the slightly lower target of 2.0-3.0. The SPAF III trial confirms that this intensity of anticoagulation is highly effective.

The search to find an effective dosing range below an international normalised ratio of 2.0 seems to be over. Future research in this subject should therefore focus on three areas. Firstly, we need to improve methods for safe management of anticoagulation in routine practice. It is important to know whether specialised anticoagulation units offer a safer service than management by individual general practices. Technical advances such as decision support for dosing and self 
monitoring by patients also require evaluation..$^{15}$ Secondly, we need to further define the risk of stroke in atrial fibrillation, perhaps using laboratory markers to supplement risk stratification based on clinical data. Thirdly, we need to develop and test safer antithrombotic drugs.

Tim Lancaster General practitioner

Jonathan Mant Clinical lecturer in public health medicine

Division of Public Health and Primary Care, Radcliffe Infirmary,

Oxford, OX2 6HE

(email: Tim.Lancaster@dphpc.ox.ac.uk)

Daniel E Singer Associate professor of medicine

Harvard Medical School, General Internal Medicine Unit, Massachusetts General Hospital, Boston 02114, MA, USA

TL is supported by the Imperial Cancer Research Fund. DES has received funding from Dupont Merck Pharmaceuticals and honoraria from Boehringer Mannheim Corporation.

1 Wolf PA, Abbott RD, Kannel WB. Atrial fibrillation: a major contributor to stroke in the elderly. The Framingham study. Arch Intern Med 1987;147:1561-4.

2 Atrial Fibrillation Investigators. Risk factors for stroke and efficacy of antithrombotic therapy in atrial fibrillation. Analysis of pooled data from five randomised controlled trials. Arch Intern Med 1994;154:1449-57.

3 European Atrial Fibrillation Trial Study Group. Secondary prevention in non-rheumatic atrial fibrillation after transient ischaemic attack or minor stroke. Lancet 1993;342:1255-62.

4 Sweeney KG, Gray DP, Steele R, Evans P. Use of warfarin in non-rheumatic atrial fibrillation: a commentary from general practice. $\mathrm{Br}$ J Gen Pract 1995;45:153-8.

5 Hylek EM, Skates SJ, Sheehan MA, Singer DE. An analysis of the lowest effective intensity of prophylactic anticoagulation for patients with nonrheumatic atrial fibrillation. N Engl J Med 1996;335:540-6.

6 Stroke Prevention in Atrial Fibrillation Investigators. Adjusted-dose warfarin versus low-intensity, fixed-dose warfarin plus aspirin for high-risk patients with atrial fibrillation: stroke prevention in atrial fibrillation III randomised clinical trial. Lancet 1996;348:633-8.

7 Atrial Fibrillation Investigators. The efficacy of aspirin in patients with atrial fibrillation: analysis of pooled data from three randomised trials. Arch Intern Med (in press).

8 Stroke Prevention in Atrial Fibrillation Investigators. Warfarin versus aspirin for prevention of thromboembolism in atrial fibrillation: stroke prevention in atrial fibrillation II study. Lancet 1994;343:687-91.

9 Hylek EM, Singer DE. Risk factors for intracranial hemorrhage in outpatients taking warfarin. Ann Intern Med 1994;120:897-902.

10 Fihn SD, McDonell M, Martin D, Henikoff J, Vermes D, Kent D, White RH. Risk factors for complications of chronic anticoagulation. A multicenter study. Warfarin Optimized Outpatient Follow-up Study Group. Ann Intern Med 1993;118:511-20.

11 Laupacis A, Albers G, Dalen J, Dunn M, Feinberg W, Jacobson A. Antithrombotic therapy in atrial fibrillation. Chest 1995;108:352-9S.

12 Rosenberg W, Donald A. Evidence based medicine: an approach to clinical problem-solving . BMJ 1995;310:1122-6.

13 The European Atrial Fibrillation Trial Study Group. Optimal oral anticoagulant therapy in patients with nonrheumatic atrial fibrillation and recent cerebral ischaemia. $N$ Engl J Med 1995;333:5-10.

14 Rosendaal FR. The Scylla and Charybdis of oral anticoagulant treatment. N Engl J Med 1996;335:587-9.

15 Fitzmaurice DA, Hobbs FD, Murray JA. Monitoring oral anticoagulation in primary care. $B M J 1996 ; 312: 1431-2$.

\title{
Medical associations: guilds or leaders?
}

\author{
Either play the role of victim or actively work to improve healthcare systems
}

$\mathrm{I}$ n many Western nations traditional medical associations are encountering an opportunity in threat's clothing. If they see through the disguise, and act accordingly, they can lead health care. If they do not, they may find themselves bewildered by their sense of helplessness.

The opportunity comes from the social need for better health care. Any honest review of the literature in clinical science and health services research must conclude that there is a large gap between how health care could perform and how it does perform. In medical care error rates are too high, waste is too pervasive, technically correct clinical services are too often withheld, and technically incorrect procedures are too often used. ${ }^{1}$ Service characteristics of health care-such as waiting times, consistency of response, and attention to dignity-are well below those of many other industries. ${ }^{2}$ The patients whom we serve are neither insatiable nor ungrateful when they demand that we do better, although that demand is becoming more strident, inducing new forms of surveillance, regulation, market pressure, and media attention.

Therein lies the opportunity for new leadership from medical associations: not to explain why we cannot do better but to set about the task of leading improvements. Unfortunately (because it makes the job harder), leading improvement requires most medical associations to change both their attitude and agenda. The change in attitude is necessary because the associations' traditional aim-to perfect and protect the profession-will not suffice to meet the social need for improved care. To improve health care we require not better professions but better systems of work.
A "system" in this sense is a set of elements interacting to achieve a shared aim. Here is the trick: to improve the performance of a system, you need to attend more to the interactions than to the elements. ${ }^{3}$ Great doctors do not make great health care. Great doctors interacting well with all of the other elements of the healthcare system make great health care. Medical associations that wish to lead socially responsive improvements in technical care, service, outcomes, and costs have no choice but to invest in improving interdependency among individuals, professions, and organisations. This is not their traditional concern.

The following principles guide the best modern approaches to system improvement. They must become the principles that guide the work of professional associations as well.

(1) Improvement requires clear aims for improvement. Complex systems, involving many people and elements, do not improve without a clear agenda for improvement. Errors in administration of medications, currently at seven per 100 hospital admissions, ${ }^{4}$ will not decline until system leaders, including medical associations, intend them to decline.

(2) Improving a system requires system leadership. You cannot lead a system towards better interactions by defending your prerogatives. Indeed, the first act of leadership towards improving a system is often to subordinate visibly and publicly your prerogatives in the service of that aim. Doctors tend not to be good at this. Their critical faculty-the ability to show what is wrong with an idea-is better developed than their contributory faculty - the ability to find something they can do 
to advance the common cause. They are better hecklers than citizens.

(3) Measuring progress is an essential activity in pursuing improved systems. Medical associations, like the legal and social contexts in which they exist, are far more familiar with measurement as an assessment or judgment than as a learning activity. Because of this, doctors, like others, tend to regard measurement of performance as a threat. In their new role as system leaders, both individual doctors and medical associations will need to embrace the measurement of performance as a step in their own learning.

(4) All improvement of systems requires changes in those systems: one definition of insanity is "doing the same thing over and over again and expecting a different result." Medical associations that fight to maintain the status quo will thereby be champions of the current level of performance. To agree wholeheartedly to lead improvement requires a commitment to change the existing methods of work continually.

(5) Not all changes are improvements. Therefore, changes in systems must be tested in real life. The challenge for professional leaders is to create and sustain a context for themselves and others that welcomes and encourages the testing of new approaches to work. Clinging too tightly to "the way we do things, and always have, around here" is no formula for improvement.

(6) Sociologically, professions tend to reservethe right to judge the "quality" of their own work. The best route to the future is for the medical profession to externalise the definition of "quality." This is not to say that patients should, or would care to, choose their own drugs, diagnoses, or surgical procedures. It is to say that the ultimate measure by which to judge the quality of a medical effort is whether it helps patients (and their families) as they see it. Anything done in health care that does not help a patient or family is, by definition, waste, whether or not the professions and their associations traditionally hallow it.

(7) Reducing waste is consistent with the pursuit of "quality." To see waste as both pervasive and as "non-quality" is characteristic of modern systems thinking as applied to all industries, and it should be so in health care. For medical associations, this means embracing cost reduction as part of their mission, not rejecting it as an external threat.

(8) Inspection alone cannot improve quality. Since performance is a characteristic of a system, you cannot "select" or "judge" a system into improving. The best you can get from inspection is to harvest the best of the status quo. For health care, that is nowhere near good enough. The widespread initiatives in both public policy and association activity in many Western nations to increase the stringency of surveillance and accreditation will never guide their healthcare systems into new performance levels. Inspecting bridges to see if they are about to fall down does not make future bridges better; it only makes current bridges safer. Inspection is important for safety, but unless it is linked to strategies for improvement it produces tremendous waste and timid aspirations.

Doctors and their medical associations have a choice: to become citizens in system improvement or to play the role of victim. For those associations that prefer the former, here are some steps to take as soon as possible.

(1) Define an agenda of improvement. State and restate publicly a clearly defined and continually revised list of aims for improving care. Promise improvement. The agenda for improvement should specifically unify the pursuit of cost reduction (that is, reducing waste) with the pursuit of better service and outcomes.

(2) Welcome, and participate in establishing, systems of measurement to monitor social progress toward achieving those improvement aims. Avoid reliance on surveillant, judgmental measurement; the measurements we need are those that can guide our own progress. Medical associations should not confuse accreditation, discipline, or certification with improvement; they are not the same.

(3) Define continually the scientific basis for change. Medical associations should not so much defend the old work as define the new work. For example, when new and effective approaches to managing asthma are published, medical associations should be among the first to call for all doctors to adopt those approaches. If committed to reducing errors in treatment, medical associations should be among the first to state the principles of system design and engineering of human factors that should constitute the new standards for professional behaviour.

(4) Promote widespread tests of change in local work processes. Medical associations should promote local innovations in care and take responsibility for spreading information on lessons learned.

(5) Break down barriers between disciplines and between organisations. Medical associations should sponsor forums in which all who want to improve health care are welcome to do so together as equals; and in those contexts they should be the first to show evidence of their willingness to subordinate their own self interest and traditional habits in the service of common aims. Nurses, managers, paramedical staff, pharmacists, and others should feel welcome as equal co-professionals in the efforts of medical associations to improve care. There is merit in maintaining the pride and dignity of a well organised profession, but there is equal merit in creating a context for cooperation among professions.

Welcome or unwelcome, the choice presses itself on medical associations throughout the world. They can behave as guilds, or they can behave as leaders toward new and better systems of care. They cannot do both, and healthcare systems as a whole may hang in the balance.

\section{Donald M Berwick President}

Institute for Healthcare Improvement, 135 Francis Street, Boston MA 02215 , USA

1 Berwick DM. Eleven worthy aims for clinical leadership of health system reform. JAMA 1994;272:797-802.

2 Nolan T, Schall MW, Roessner J. Reducing delays and waiting times through out the healthcare system. Boston MA: Institute for Healthcare Improvement, 1997.

3 Langley GJ, Nolan KM, Nolan TW, Norman CL, Provost LP. The improvement guide: practical approach to enhancing organisational performance. San Francisco: Jossey-Bass Publishers, 1996

4 Bates DW, Cullen DJ, Laird NM, Petersen LA, Small SD, Servi D, et al. Incidence of adverse drug events and potential adverse drug events: implications for prevention. JAMA 1995;274:29-34.

5 Womack JP, Jones DT. Lean thinking: banish waste and create wealth in your corporation. New York: Simon and Schuster, 1996. 


\title{
Should trusts be allowed to fail?
}

\author{
If failure is inevitable, the process should be planned and managed
}

$\mathrm{T}$ he logic of competition and the inevitable product of collaboration in healthcare markets is that there will be winners and losers. At present, Britain's self governing NHS trust hospitals compete to provide services for patients, and the loss of contracts, for whatever reason, makes their viability uncertain. This was recognised in the government's original white paper on the internal NHS market, ${ }^{1}$ which stated that the assets would revert to the ownership of the secretary of state if a trust was wound up. It has now been reported that Anglian Harbour NHS Trust will be dissolved on 31 August after losing contracts to neighbouring trusts. ${ }^{2}$ The viability of many other trusts in other places is in doubt, and they await the decisions of the new government to determine their fate.

The contraction of the hospital sector is not new. A recent report from the University of London notes that the number of acute beds in London has fallen by $41 \%$ in 12 years. ${ }^{3}$ Similar trends are evident in the rest of England, where the bed stock fell by $25 \%$ between 1984 and 1994. ${ }^{4}$ During 1959-90 the number of non-psychiatric hospitals in England fell by $45 \%$ to 1185. Since 1990 a further 60 acute hospitals have closed. ${ }^{5}$

These reductions are a product of changes in the pattern of disease and morbidity and of technological innovation, in particular the rapid development of day surgery and continuing downward pressure on length of stay. The scope for further reductions in length of stay may be considerable. In California, health economists are arguing that a ratio of bed stock to population of 2.5 per 1000 is adequate. ${ }^{6}$ This compares with the English figure of 2.97 beds per 1000 population, implying the need for further changes in both hospital bed stock and community support of earlier discharged patients.

It is likely that the NHS will continue to be funded out of taxation, but this does not mean that provision will not be privatised. A minister in the previous administration recently refused to rule out the use of the private sector to provide care for NHS patients, arguing that what mattered was the maintenance of a service which was largely free at the point of delivery. ${ }^{7}$ The problem with a privately provided though publicly subsidised healthcare system is that it carries high regulation costs and does not ensure equity. The overprovision necessary to ensure a competitive market does not seem, at least from the American experience, to provide a better answer than a sensibly decentralised public enterprise. ${ }^{8}$ With over half of private sector beds now in NHS hospitals, and with this trend likely to increase as trusts strive to generate profits from private activity to fund NHS care, the public-private mix in the provision of care is likely to become more complex.

Any answer to the question, "Should trusts be allowed to fail?" depends on the policy objectives of government. The funding of the NHS hospital and community health services system is determined by a needs based capitation formula. The new government will use a needs based capitation formula to equalise primary care funding. Such formulas will move resources from the south to the north and from rural to urban areas. ${ }^{9}$ Existing "levies" to support expensive urban teaching hospitals may be eroded. If the government wants explicit and equitable funding and increased efficiency-in future measured in terms of patient outcomes ${ }^{10}$ - a radical reconfiguration in the hospital stock is unavoidable: a considerable number of NHS trusts will fail.

This failure process will need to be planned carefully. Trusts which are essential for the health of the local population but which have poor management will need better control. Issues of scale will have to be confronted: if there is a relation between volume of activity and mortality, units should be of the necessary size; but where there is no evidence of such a relation, ${ }^{11}$ smaller scale production to strictly enforced protocols may be sufficient. The royal colleges will have to use such information carefully to introduce flexibility into their training programmes. Openness, speed, and careful use of the evidence base in terms of costs and benefits $^{12}$ are essential if scarce NHS assets are not to be wasted.

The quality of NHS management will be tested by these challenges. Careful planning is required, rather than a cavalier parochial approach to the rationalisation of the trust stock. Management has been deficient in some places, with failure to discuss the issue openly and explicitly, or to implement-for whatever reason, political or otherwise- the changes identified as necessary. Placing both patient care and trusts' viability in jeopardy by such management is unfortunate and unnecessary.

\section{Chantler Children Nationwide professor of paediatric nephrology}

United Medical and Dental School, Guy's Hospital, London SE1 9RT

A Maynard Professor of economics

Department of Economic and Related Studies, University of York, York YO1 5DD

\footnotetext{
Department of Health. Working for patients. London: HMSO, 1989:26

2 News in Brief. BMJ 1997;314:536.

The contribution of London's academic medicine to healthcare and the economy. London: Medical Office, University of London, 1997:60.

4 Department of Health. Health and social services statistics. London:HMSO, 1996.

5 Harrison A, Prentice S. Acute futures. London: King's Fund, 1996

6 Enthoven AC, Singer SJ. Managed competition and the Californian health care economy. Health Affairs 1995;15(1):39-57.

7 Anonymous. Hospital Doctor 1997 February 27:52.

8 Woolhandler S, Himmelstein DU. Costs of care and administration at for profit and other hospitals in the United States. $N$ Engl J Med 1997;336:769-74.

9 Peacock S, Smith P. The resource allocation consequences of the new NHS needs formula. York: Centre for Health Economics, University of York, 1995. (Discussion paper 135.)

10 Department of Health. The National Health Service: a service with ambitions. London: Stationery Office, 1996. (Cm 3425.)

11 NHS Centre for Reviews and Dissemination. Hospital volume and health care outcomes, costs and patient access. Effective Health Care Bulletin $1996 ; 2(8)$.

12 Maynard A. Evidence based medicine: an incomplete method for informing treatment choice. Lancet 1997;349:126-8.
} 


\title{
British doctors are not disappearing
}

\author{
But career patterns are changing
} ing medicine. Last autumn, for example, $B M A$ News Review declared, "Atrocious conditions force new doctors out of medicine" after an interview with the chairman of the General Medical Council's education committee. Yet we can find no evidence for statements that up to a quarter of doctors are leaving medicine within a few years of graduation. The loss is much smaller, and much is not permanent. Three separate questions have become confused: How many medical students do not complete the course? How many doctors leave medicine and at what stage? How many doctors leave the UK and therefore the NHS?

Analysis of figures derived from the Universities and Colleges Admissions Service, the GMC, ${ }^{1}$ and other sources indicate to some observers that about $7 \%$ of medical students do not complete the course ${ }^{2}$ and to others that "at least 12\%" do not. ${ }^{3}$ About half of these students fail their exams and about half change their minds; a few fail because they changed their minds. Seven per cent is low for any professional or university course and would be hard to improve on, but clearly we need to know precisely what the wastage is so that it can be taken into account in setting intake figures.

It is clear that no significant loss occurs in the year after qualification (the preregistration year). In 1996 only $1 \%$ of 1993 qualifiers and 1.2\% of 1994 qualifiers had not proceeded to full registration (GMC, personal communication). At the end of their preregistration year very few UK qualifiers from 1974, 1977, 1980, 1983,1988 , and 1993 were intent on a career outside medicine. ${ }^{4}$ Even when those considering leaving medicine are included the figure is less than $5 \%{ }^{4}$

At five years after qualification 5.3\%-8.8\% of the UK graduates of 1974, 1977, 1980, 1983, and 1988 were known not to be in medical practice but most had not started other careers: they were between jobs or taking time out. Adding these figures to the UK qualifiers from those cohorts who were in medical practice outside the UK, the overall known loss of doctors to the UK after five years was between $8.8 \%$ and $17 \%$ (the highest figure $17 \%$ applying to the 1974 qualifiers compared with $13.7 \%$ of the 1988 qualifiers) (M J Goldacre, personal communication). Allen's surveys show that only $2 \%$ of 1981 qualifiers were not working in medicine or a medically related occupation five years later, ${ }^{5}$ but this figure had risen to $7 \%$ among 1986 qualifiers interviewed in $1991 .^{6}$ Most of these were, however, between jobs or were women temporarily not working because of family commitments.

In short there is no evidence that medical schools are recruiting young men and women unable to stand the pace as junior doctors. Even in the University Hospitals Association survey of 1987, which elicited trenchant criticisms from nearly half those questioned about their working conditions and training, 90\% felt that their career was on target. ${ }^{7}$ It would be surprising if young doctors did not at some time have doubts about their career or be attracted by opportunities abroad. An article by Lambert et al in this week's issue

(p 1591) shows that an unprecedented number of 1993 qualifiers were undecided about whether to practise in the UK. ${ }^{8}$ Fortunately there is some evidence that the lot of young doctors is beginning to improve. ${ }^{9}$ This is not before time: without sustained improvement the risk of doctors disappearing from medicine is real. Many are highly critical and disaffected.

Although doctors may not be giving up medicine, the reduction in applications for posts, especially in general practice, suggest that some have given it up for a while. About $60 \%$ of 1995 graduates questioned in 1996 were intending to travel or practise overseas temporarily. ${ }^{10}$ Doctors may also be reluctant to commit themselves to training programmes from which it is becoming increasingly difficult to move sideways. Many, and not only women, want flexible training and properly designed and funded part time medical work.

A striking aspect of medical workforce planning is the failure to acknowledge this demand for changing patterns of work-or to track it in workforce statistics. How can a nation that invests about $£ 200000$ to train each doctor fail to keep systematic records of where they are or what they are doing? The medical manpower record of the Department of Health ${ }^{11} 12$ provided data for the two reports of the Medical Workforce Standing Advisory committee, ${ }^{13}{ }^{14}$ but the same data were used for both since the record had not been updated..$^{14}$ In spite of concern about an exodus of doctors no new data were being collected.

Even if the manpower record had been updated its accuracy would have been questionable. It counted only doctors working in the NHS and universities and made no attempt to obtain information from doctors themselves. In 1986 when a check was made on a random sample of the 43262 doctors on the Medical Register who were not on the manpower record about 8600 were estimated to be working in the NHS and a further 7000 in medical posts outside the NHS. ${ }^{15}$ Those 15600 "missing" doctors are equivalent to nearly $l$ in 10 of those on the register. The manpower record has now been replaced by the medical workforce flows system, which models flows but does not focus on the career intentions of individual doctors or cover all doctors in the UK.

Complex statistical models based on inaccurate numbers are pointless. What is needed is a medical census, carried out at least every five years, of all UK doctors, including their date of birth, specialty, and career plans. The Medical Workforce Standing Advisory Committee, entrusted with forecasting the UK's future need for doctors, deserves better equipment than a crystal ball.

Peter Richards Medical director

Northwick Park and St Mark's NHS Trust, Harrow, HA1 3UJ

Chris McManus Professor of psychology

Imperial College School of Medicine at St Mary's, London W2 1PG

Isobel Allen Head of social care and health studies

Policy Studies Institute, London NW1 3SR 
1 General Medical Council. Commentary on the second survey of medical education practices in UK medical schools. London: GMC, 1992.

2 McManus IC. Drop out rate in medical schools seems reasonable. BMJ 1996;313:173.

3 Parkhouse J. Intake, output and drop out in UK medical schools. BMJ $1996 ; 312: 885$.

4 Lambert TW, Goldacre MJ, Edwards C, Parkhouse J. Career preferences of doctors who qualified in 1993 compared with those of doctors qualifying in 1974, 1977, 1980 and 1983. BMJ 1996;313:19-24.

5 Allen I. Doctors and their careers. London: Policy Studies Institute, 1988.

6 Allen I. Doctors and their careers: a new generation. London: Policy Studies Institute, 1994.

7 Richards JDM, Richards P. An enquiry by the University Hospitals Association into the progress and career perceptions of doctors within 6 years of graduation. University Hospitals Association (unpublished), 1989.
8 Lambert TW, Goldacre MJ, Parkhouse J. Intentions of newly qualified doctors to practise in the United Kingdom. BMJ 1997;314:1591-2.

9 Paice E, West G, Cooper R, Orton V, Scotland A. Senior house officer training: is it getting better? BMJ 1997;314:719-20.

10 Ford J. On the early career choices of medical graduates. BMJ 1997;314:Classified supplement 29 Mar:S2.

11 Department of Health and Social Security. Medical Manpower-the next twenty years. London: HMSO, 1978.

12 Department of Health. Report of the Second Advisory Committee of Medical Manpower Planning. London: Department of Health, 1989.

13 Medical Manpower Standing Advisory Committee. First Report:planning the medical workforce. London: Department of Health 1992.

14 Medical Workforce Standing Advisory Committee. Second Report: planning the medical workforce. London: Department of Health, 1995.

15 Nicholl JP, Williams BT. Employment outside the NHS of doctors registered in the United Kingdom. BMJ 1988;297:112.

\title{
Tackling deficient doctors
}

\author{
Mentoring and appraisal may stave off calls for reaccreditation
}

$\mathrm{W}$ hen asked "Have we lost faith?" George Bernard Shaw replied, "Certainly not; but we have transferred it from God to the General Medical Council."' The UK continues to rely on self regulation among doctors, but, in the wake of increasing public concern about standards of medical practice and the profession's ability to deal with problem doctors, the GMC has moved from reactive to proactive mode. Instead of merely wagging the finger and telling doctors what they should not do, the council has made a determined attempt to forge an explicit view of how doctors should practise to the highest standards. ${ }^{2}$

This sea change in professional thinking was clearly demonstrated with the publication of Good Medical Practice in $1995^{3}$ and was entirely complementary to the fresh thinking on undergraduate medical education demonstrated by the council's earlier guidance, Tomorrow's Doctors. ${ }^{4}$ Having successfully articulated positive values and standards, the GMC then faced the challenge of dealing with the small proportion of doctors whose standard of practice or behaviour was not so catastrophic as to constitute serious professional misconduct but who, none the less, were unable to command the confidence of patients or colleagues.

The difficulty of dealing satisfactorily with this group of doctors has been exacerbated by the NHS reforms, which have created a plethora of employing bodies and diluted existing expertise in dealing with medical disciplinary issues. The need for change is clear from the attitudes of some doctors to the failings of their colleagues, the great difficulty in tackling these problems effectively, and the frustration created by attempts to use existing mechanisms. ${ }^{5}$ In this week's $B M J$ (p 1613) the council's president, Sir Donald Irvine, describes the response to this challenge through the introduction of new performance review procedures. ${ }^{6}$

While a vital step forward towards active self regulation, the new procedures are not without difficulty. They are intended to be used only when local resolution has been unsuccessful. Yet local resolution depends on the skills and knowledge of NHS trusts' medical directors and directors of public health, and the people entering these posts are given little system- atic training. ${ }^{7}$ The crucially important interface between the GMC's procedures and the NHS clearly needs improving, perhaps by the creation of local networks.

However, the biggest test for the NHS will come when a doctor whose performance is judged to be deficient is required to improve, a requirement which might include retraining. The GMC will place the responsibility squarely on the individual doctor to take the necessary remedial action. In many instances this will require the active cooperation of professional colleagues and employers. At a time when Britain is facing serious shortages in the medical workforce, it would be foolish as well as unjust to give anything less than adequate support to individuals genuinely trying to remedy deficiencies in their performance.

The GMC has set out the principles that should infuse undergraduate medical education and postgraduate training and practice. It has also now created the mechanisms for dealing with serious deficiencies in performance. But there is a clear need for further preventive work. Mentoring and appraisal have an important contribution to make. ${ }^{8}$ This is well accepted for doctors in training, but is much less accepted for doctors in more senior positions. The GMC's new performance procedures may stave off demands for reaccreditation, but this breathing space must be used constructively if prevention is to be taken as seriously as cure.

\section{Gabriel Scally Regional director of public health}

South and West Region, NHS Executive, Bristol BS12 6SR

\footnotetext{
1 Shaw GB. Doctors'delusions, crude criminology and sham education. London: Constable, 1932

2 Irvine DH. The performance of doctors. I: Professionalism and self regulation in a changing world. BMJ 1997;314:1540-2.

3 General Medical Council. Duties of a doctor: good medical practice. London: GMC, 1995.

4 General Medical Council. Tomorrow's doctors: recommendations on undergraduate medical education. London: GMC, 1993.

5 Rosenthal MM. The incompetent doctor: behind closed doors. Buckingham: Open University Press, 1995.

6 Irvine DH. The performance of doctors. II: Maintaining good practice, protecting patients from poor performance. BMJ 1997;314:1613-5.

7 Wood TJ, Scally G, O'Neill D. Management skills and knowledge required by medical directors. Clinician in Management 1995;4(4):2-5

8 Department of Health. Maintaining medical excellence: review of guidance on Department of Health. Maintaining medical excellence:
doctors 'performance. Leeds; NHS Executive, 1995.
} 